\title{
Diverging Populations and Endogenous Growth in a Model of Meaningless Trade
}

\author{
Alan V. Deardorff*
}

\begin{abstract}
The endogenous growth literature raises the possibility that countries may grow without bound in terms of per capita income, and that they may do so at different rates. This possibility also exists in neoclassical growth models with diverging populations-populations that grow at different rates. In both cases, however, this means that international inequality of per capita incomes will not only exist but also get worse over time. This paper examines that possibility within a very simple one-sector model that allows for both diverging populations and endogenous growth.
\end{abstract}

\section{Introduction}

The "New Growth Theory," characterized by growth rates that depend even in the long run on savings and other parameters of behavior and thus "endogenous growth," has caused a revival in a literature that had lain dormant for over two decades. ${ }^{1}$ In the international context, endogenous growth has been applied primarily to searching for a better understanding of how international trade and investment may influence national growth. However, endogenous growth also has a much more straightforward implication that I seek to explore in this paper. If countries can grow indefinitely at different rates, then their per capita incomes will grow further and further apart, implying increasing international inequality and perhaps an increase in envy, resentment, and conflict among nations. That is a concern that I noted earlier in Deardorff (1994), where I observed that even without the usual mechanisms for endogenous growth such as endogenous learning-by-doing and technological progress, the presence of differences in population growth rates across countries can give rise to the same phenomenon. In this paper I combine that paper's assumption of diverse population growth rates-what I call diverging populations-with a very simple model of endogenous growth. My purpose is to examine the circumstances under which international inequality will emerge and even increase over time. ${ }^{2}$

The growth model examined here will be of the "AK" variety. ${ }^{3}$ That is, endogenous growth will be made possible by assuming a technology that includes a lower bound on the marginal product of capital in producing new capital. In such a model, if enough output is saved and invested, it may be possible for the capital stock to grow indefinitely relative to the labor force. I incorporate this assumption into the simplest possible model of a world economy, one in which there is only one homogeneous good. Such a model would not normally be thought to include trade, but I will allow for trade anyway, and also on occasion international direct investment, both of which will be assumed to arise randomly when free markets make international transactions a matter of indifference. Since this trade does not actually accomplish anything that could not

\footnotetext{
* Deardorff: University of Michigan, Ann Arbor, MI 48109, USA. Tel: (734) 764-6817; Fax: (734) 76309181; E-mail: alandear@umich.edu. I have benefited from discussions on this topic with Pat Deardorff, Bob Stern, and participants at the Hong Kong conference.
} 
be done without trade, I call this a model of "meaningless" trade. However, I show later in the paper that it behaves similarly to other more standard models of trade. Indeed, it is equivalent to a version of Krugman's (1979) model of trade with monopolistic competition that is the cornerstone of much of the New Trade Theory.

In section 2, I analyze this meaningless trade model, leading to a table of results (Table 2) that I work through in the text. Since the model includes a number of objectionable assumptions, I examine some of these in section 3, where I try to convince the reader that the model is not as silly as it may at first sound. Section 4 concludes.

\section{The Growth Model with Meaningless Trade}

The simple version of the AK model that I will use is as follows: Country $i$ produces a homogeneous product, $Y^{i}$, using inputs of capital, $K^{i}$, and labor, $L^{i}$, in a production function that has a lower bound, $b$, on the marginal product of capital. For simplicity I go further than that, letting the production function be linear:

$$
Y^{i}=a L^{i}+b K^{i}
$$

The labor force grows with population at a constant rate, $n^{i}$ :

$$
\dot{L}^{i}=\frac{d L^{i}}{d t}=n^{i} L
$$

while the capital stock grows with investment, $I^{i}$ :

$$
\dot{K}^{i}=\frac{d K^{i}}{d t}=I^{i}
$$

\section{Growth of Individual Countries}

In principle I will sometimes allow for international investment, but right now there is no reason for it, since the return to capital is its marginal product, $b$, and equal across countries. Therefore I assume for now that the source for domestic investment is domestic savings, which I take to be a constant fraction of national income, $Y^{i}$ :

$$
I^{i}=s^{i} Y^{i} \text {. }
$$

Suppose initially that there is no trade or other interaction between the countries. Then this is an example of the familiar AK model of a closed economy that was introduced by Solow (1956). ${ }^{4}$ Equations (1)-(4) combine to yield a single differential equation in the capital-labor ratio, $k^{i}=K^{i} / L^{i}$ :

$$
\dot{k}^{i}=\frac{d k^{i}}{d t}=s^{i} a+\left(s^{i} b-n^{i}\right) k^{i} .
$$

The solution to this equation is

$$
k^{i}(t)=\left(k_{0}^{i}-k^{i^{*}}\right) e^{\left(s^{i} b-n^{i}\right) t}+k^{i^{*}},
$$

where $k_{0}^{i}$ is the country's initial capital-labor ratio and $k^{i^{*}}$ is given by

$$
k^{i^{*}}=\frac{-s^{i} a}{s^{i} b-n^{i}},
$$

which turns out to be the steady-state capital-labor ratio in the case where growth converges to a steady state. 
Specifically, let $G(x)=d(\ln x) / d t$ be the growth rate of any variable, $x$. Then the relevant properties of this solution can be summarized as in equations (8) below. Performance of a country over time depends critically on whether the exponential in equation (6) is positive or negative. Since the exponent is positive for high saving and low population growth, both of which show a certain restraint on the part of the people in the country, I refer to the countries in that case as "abstemious." The opposite case, of low saving (thus high consumption) and high population growth suggests a greater eagerness for current enjoyment, and I call these countries "hedonistic."

Hedonistic countries: If $s^{i} b<n^{i}$ then

$$
\begin{aligned}
& k^{i} \rightarrow k^{i^{*}}=\left(\frac{s^{i} a}{n^{i}-s^{i} b}\right)>0, \\
& y^{i} \rightarrow a+b k^{i^{*}}=a+\left(\frac{s^{i} a b}{n^{i}-s^{i} b}\right), \\
& Y^{i} \rightarrow \infty, \\
& G\left(k^{i}\right), G\left(y^{i}\right) \rightarrow 0, \\
& G\left(Y^{i}\right) \rightarrow n^{i} .
\end{aligned}
$$

That is, if the savings rate is low enough compared with the population growth rate, then the capital-labor ratio converges to a constant, as does the per capita income of the country, and the growth rates of both converge to zero. Variables that are not in per capita terms, however, including national income, $Y^{i}$, grow without bound, with growth rates converging to the rate of population growth, $n^{i}$.

Abstemious countries: If $s^{i} b>n^{i}$ then

$$
\begin{aligned}
& k^{i}, y^{i}, Y^{i} \rightarrow \infty, \\
& G\left(k^{i}\right), G\left(y^{i}\right) \rightarrow s^{i} b-n^{i}, \\
& G\left(Y^{i}\right) \rightarrow s^{i} b .
\end{aligned}
$$

That is, if the savings rate is high enough (only possible if $b>n^{i}$ ), then even the per capita variables grow without bound. Their growth rates converge to $s^{i} b-n^{i}$, while that of total income converges to $s^{i} b$.

The distinction between exogenous and endogenous growth can be seen in these solutions. In an exogenous growth model, either sustained per capita growth is impossible, as in the low-saving case here, or it occurs only due to exogenous technological progress, which is omitted here. In an endogenous growth model, sustained per capita growth is possible, and the rate of growth of per capita variables depends endogenously on behavior in the model, as in $(8 \mathrm{~g})$ it depends on $s^{i}$ and $n^{i}$.

\section{Trade Patterns}

So far I have allowed for no economic interaction between these countries, such as international trade or capital movements. But if I now allow for either of these, there is no positive reason for these interactions to occur. The model has only one good, so there is no incentive to exchange consumer goods. And while there could nonetheless be trade over time if one country were to invest capital in another at one time and receive returns on that investment by importing the consumer good later on, there is 
no incentive for this form of trade either, since the return to capital is fixed by assumption at $b$ in all countries.

This will not stop me, however, from extracting information about trade and capital flows from this simple model. For while there is no positive incentive to trade here, there is no reason not to, either. In Deardorff (1998), I found it useful to depart from an old convention in trade theory, which is to assume that when buyers and sellers are indifferent among sellers and buyers with whom to trade, they always resolve that indeterminacy in favor of domestic exchange. I assumed instead that agents resolve such indeterminacies randomly across all agents among whom they are indifferent, so that international trade may become as likely as domestic exchange, if not more so. I recognize that this is an extreme assumption and one that many will object to. But it is not logically more extreme than the assumption of zero transport costs and other trade barriers on which it is based, and in any case I think it bears looking at as a limiting case. As I will note in section 3, the implications are similar to some other approaches to international economic modeling that have been popular of late, and they are identical to one of them in particular. However, under my assumptions here this trade does nobody any good (or harm) and I therefore refer to this as a "meaningless" trade model.

I will consider two cases: with and without international capital flows. Consider first, then, the case of a prohibitive barrier to international capital movement but free international trade.

Without international capital flows, demanders (consumers and investors) in each country are collectively constrained to spend only their own income, but with free trade they will be indifferent among all countries' products and therefore will spend that income on the products of all countries in proportion to their outputs. It is helpful to think of producers in each country, all of which produce the same homogeneous product, as putting their outputs into a common world pool, from which demanders in each country then draw. The result is a good deal of international trade, with demanders importing a fraction of their income equal to one minus their country's share of world output, since this share is their own producers' share of the pool. Their country's producers likewise export that same fraction of their output, and trade is balanced. At each moment in time, very much as in the simple frictionless gravity equation of Deardorff (1998), exports from country $i$ to country $j$ are

$$
T^{i j}=\frac{Y^{i} Y^{j}}{Y^{w}},
$$

where $Y^{w}=\Sigma Y^{i}$ is world output.

A country's total international trade (exports plus imports) in this case is

$$
T^{i}=\sum_{j \neq i} T^{i j}+\sum_{j \neq i} T^{j i}=2 \frac{\left(Y^{w}-Y^{i}\right) Y^{i}}{Y^{w}} .
$$

Not surprisingly, this model has the property that the share of a country's GDP that it trades, $T^{i} / Y^{i}=2\left[1-\left(Y^{i} / Y^{w}\right)\right]$, depends negatively on its size relative to the world.

Now suppose alternatively that international capital flows are permitted. With equal returns to capital across countries, the normal assumption would be that capital stays home, but this too is arbitrary. If returns really are equal, then potential investors should be indifferent as to where they install their capital, and the location of capital will be indeterminate. As an alternative to keeping capital at home, I will resolve this indeterminacy by assuming that capital is allocated randomly in proportion to popu- 
lation, so that foreign direct investment (FDI) keeps the ratio of installed capital to labor the same in every country. This too can be justified with a minor modification of the model, as I will argue in section 3. Owners of capital in any country will then own it all over the world, with a portfolio that matches in its country composition the distribution of population across countries. They will be paid the competitive return to their foreign capital, $b$, which they will collect as imports of the produced good. Those imports also measure the value of the exports of capital services.

What, then, will be the trade flows at a point in time with mobile capital? We must first distinguish GNP and GDP, both of which were presented until now by $Y^{i}$. Let $K^{i}$ be the capital owned by residents of a country, and $K_{i}$ be the capital installed in that country. ${ }^{5}$ Then, since all capital earns the return $b$, GNP of country $i$ is

$$
Y^{i}=a L^{i}+b K^{i}
$$

and world output is

$$
Y^{w}\left(=Y_{w}\right)=a L^{w}+b K^{w} .
$$

Since installed capital is in the same ratio, $k^{w}=K^{w} / L^{w}$, in every country, however, GDP is

$$
\begin{aligned}
Y_{i} & =a L^{i}+b K_{i} \\
& =a L^{i}+b k^{w} L^{i} \\
& =\frac{L^{i}}{L^{w}} Y^{w} .
\end{aligned}
$$

In this model, a country's share of world income, $Y^{i} / Y^{w}$, can easily exceed or fall short of its share of world production, $Y_{i} / Y^{w}$, through ownership of capital abroad or through foreign ownership of domestic capital.

To specify international trade in this context of mobile capital, we need to clarify even further how various indeterminacies will be resolved. An owner of capital that is installed abroad who wants to invest the earnings in another foreign country could be assumed to collect its foreign earnings by importing goods, and then to export those same goods for investment somewhere else. But that would amount to no more than re-exports which, if we allow them, could proliferate unduly in the model. Instead I will assume again that all producers place their outputs into a single world pool, and that those who earn any income buy from that same pool at random for both their consumption and investment needs. They then deliver the products either for consumption to their home countries or for investment to the countries where they want to install capital; that is, to all countries in proportion to population. Thus any investment gives rise to trade flows exported from countries in proportion to production and imported into countries in proportion to population. A given trade flow between two countries may be initiated, therefore, by an investor who is not located in either of those countries.

Note that again there is no facility for borrowing or lending, and therefore no possibility of countries spending more or less than their incomes. However, there can be trade imbalances, as usually measured, since net capital flows will be matched by exports of the good (used for investment) in the same direction without any offsetting imports in the same period. The imports come later as income on that capital.

To derive trade flows, we need to consider consumption and investment separately. Let the GNP of country $j$ be divided into consumption and investment: $Y^{j}=C^{j}+I^{j}$. Consumption goods will be purchased from all countries in proportion to their pro- 
duction, as above, giving rise to exports from $i$ to $j$ equal to $\left(Y^{i} / Y^{w}\right) C^{j}$. Investment goods will be sourced in the same fashion, but they will be invested in, and therefore exported (from the source country) to, all countries in proportion to their populations. Thus the investment of country $h$ (equal to its savings rate times its income, $I^{h}=s^{h} Y^{h}$ ) gives rise to exports from country $i$ to country $j$ of $\left(Y^{i} / Y^{w}\right) I^{h}\left(L^{j} / L^{w}\right)$. Total exports from $i$ to $j$ are therefore

$$
T^{i j}=\frac{Y^{i}}{Y^{w}}\left(C^{j}+\frac{L^{j}}{L^{w}} \sum_{h} I^{h}\right) .
$$

Define the world savings rate as the GNP-weighted average of the national savings rates,

$$
s^{w}=\sum_{h} \frac{Y^{h}}{Y^{w}} s^{h},
$$

and note that investment in proportion to population implies that

$$
\frac{L^{j}}{L^{w}}=\frac{K^{j}}{K^{w}}=\frac{Y^{j}}{Y^{w}} .
$$

Equation (14) can then be rewritten as

$$
\begin{aligned}
T^{i j} & =\frac{Y^{i}}{Y^{w}}\left[\left(1-s^{j}\right) Y^{j}+s^{w} Y_{j}\right] \\
& =\frac{Y^{i} Y^{j}}{Y^{w}}\left(1-s^{j}+s^{w} \frac{Y_{j}}{Y^{j}}\right) .
\end{aligned}
$$

To understand the determinants of trade in this equation, realize first that a country's own savings has a negative effect on its imports, since whereas consumption requires mostly imports in a small country, savings and the consequent investment mostly goes into other countries and therefore requires imports into them, not into the country doing the investing. Likewise, imports depend positively on how much is produced in a country, GDP $=Y_{j}$, compared with its residents' income, $Y^{j}$, since production is proportional to the labor force and new investment, which in turn uses imports.

Equation (17) says that trade will be given by the simple frictionless gravity equation if both of the following are true: the savings rate of the importing country equals that of the world, and the importing country has GNP equal to GDP; i.e., it has no net capital flows. ${ }^{6}$ Trade between two countries will exceed the simple gravity prediction if the importing country saves less than the world, since it will then be a big consumer and therefore importer; and/or if the importing country is a net host to foreign capital, since its imports for investment purposes will be greater than predicted from its own income and savings.

\section{Growth Effects}

Now consider what happens to output and trade over time as the countries follow the growth paths stated earlier in equations (8). There are several cases to consider, depending on the characteristics of the countries involved. These are summarized in Table 2, using the identification of certain benchmark countries that appears in Table 1. Specifically, I denote by $\bar{l}$ and $\tilde{l}$ the countries with the highest population growth and 
savings rates, respectively, $\bar{n}$ and $\tilde{s}$ being the corresponding rates. Also, looking at per capita income, among hedonistic countries (which do converge to a steady state in per capita terms), I denote by $\hat{\imath}$ the country with the highest steady-state per capita income, while among abstemious countries I denote by $\hat{\imath}$ the country that tends toward the highest growth rate in per capita income. Countries that save more of their incomes than the world average savings rate defined in (15) are denoted with a forward arrow, while those that save less than the world average are denoted by a backward arrow. Throughout Table 2, rather than squeeze any of these indicators on to country superscripts, $i$, an indicator placed directly over any variable denotes that country, as indicated in the footnote to Table 2.

Table 2 then records the ultimate behavior of various shares and other variables that may be informative for the issues raised in the introduction. Specifically, it reports shares of world population, income, and production for countries, indicating whether these are (or asymptotically approach) a constant or the extreme values of zero and one. In the latter case, it indicates which of the benchmark countries, if any, come to dominate the world in the sense of having a share of one.

Next the table reports the behavior of trade shares-exports and imports-not as fractions of world trade but as fractions of a country's own production or income. Again, these shares may become constant at intermediate values between zero and one, or they may converge to zero or one themselves, indicating that trade will appear to become either more or less important over time for the country. The table also includes the ratio of a country's owned capital to the capital installed there, thus indicating its net capital position and therefore its reliance either on capital abroad for income or on foreign-owned capital for production. Of course, in this meaningless trade (and investment) model, neither trade nor foreign direct investment play any substantive role and could be replaced by domestic sourcing and investment without cost. However, these ratios are likely, I believe, to approximate their values in various more complex models where trade and FDI do play real roles, as I will argue in section 3. More important, perhaps, they indicate the sources of international friction that may arise when international disparities in income are accompanied by extreme reliance on trade and/or FDI.

Finally, Table 2 reports what happens to perhaps the most important variable in this model, per capita income. Only that of the most "successful" country is reported, and there only to say whether it approaches a constant or instead grows without bound. More important, however, is the indicator of which country it is that occupies this role, which varies across the cases considered. The final row of Table 2 then reports what happens to a measure of relative poverty, taken to be the ratio of per capita income in a given country to that of the country with the highest per capita income. Again, in this model, the actual performance of every country is independent of both the behavior of other countries and of the permissible interactions among them. Nonetheless, it is relative performance that often gives rise to concern by the public, and I would expect these conclusions to extend to many more complex models that allow for such interdependencies.

The columns of Table 2 correspond to the cases considered. The first four, in columns (3)-(6), concern a world of only hedonistic countries, which therefore all converge to steady states, their per capita variables approaching constants. The last four columns allow for abstemious countries, and therefore endogenous growth. To explore the role of diverging populations, both sets of cases are divided into ones in which all countries share the same population growth rate and ones where they do not. Finally, each of the resulting four cases are in turn divided into ones without international capital 
Highest Savings Rate

Highest Steady State Per Capita Income and CapitalLabor Ratio

Highest Asymptotic Per Capita Growth Rate
Corresponding Parameter

$$
\begin{aligned}
& \bar{i}=\underset{i}{\arg \max } n^{i} \\
& \widetilde{i}=\arg \max s^{i}
\end{aligned}
$$$$
\hat{i}=\underset{i}{\arg \max }\left(\frac{s^{i} a}{n^{i}-s^{i} b}\right)=k^{i^{*}}
$$$$
\hat{\hat{i}}=\underset{i}{\arg \max }\left(s^{i} b-n^{i}\right)=G\left(y^{i}\right)
$$$$
\bar{n}=\max n^{i}
$$$$
\widetilde{s}=\max s^{i}
$$$$
\hat{k}^{*}, \hat{y}^{*}
$$

Countries with Higher and Lower Savings Rates than the World Average

$\vec{i}: \quad s^{i}>s^{w}, \quad \bar{i}: \quad s^{i}<s^{w}$ 


\begin{tabular}{|c|c|c|c|c|c|c|c|c|c|}
\hline & & \multicolumn{4}{|c|}{ All Countries Hedonistic: $s^{i} b<n^{i}, \forall i$} & \multicolumn{4}{|c|}{ Some Countries Abstemious: $s^{i} b>n^{i}$, for some $i$} \\
\hline & & \multicolumn{2}{|c|}{$\begin{array}{l}\text { Equal Population Growth } \\
\quad \text { Rates, } n^{i}=n, \forall i\end{array}$} & \multicolumn{2}{|c|}{$\begin{array}{c}\text { Unequal Population Growth } \\
\text { Rates, } n^{i} \neq n, \forall i\end{array}$} & \multicolumn{2}{|c|}{$\begin{array}{l}\text { Equal Population Growth } \\
\quad \text { Rates, } n^{i}=n, \forall i\end{array}$} & \multicolumn{2}{|c|}{$\begin{array}{c}\text { Unequal Population Growth } \\
\text { Rates, } n^{i} \neq n, \forall i\end{array}$} \\
\hline & & No FDI & $F D I$ & NoFDI & $F D I$ & No FDI & $F D I$ & NoFDI & $F D I$ \\
\hline (1) & $(2)$ & (3) & (4) & (5) & (6) & (7) & $(8)$ & (9) & $(10)$ \\
\hline $\begin{array}{l}\text { Shares* of } \\
\text { World } \\
\text { Population }\end{array}$ & $\lambda^{i}=\frac{L^{i}}{L^{w}}$ & \multicolumn{2}{|c|}{$\lambda^{i}=\frac{L_{0}{ }^{i}}{L_{0}{ }^{w}}=\mathrm{const}$} & \multicolumn{2}{|c|}{$\begin{array}{l}\bar{\lambda} \rightarrow 1 \\
\lambda^{i} \rightarrow 0, \quad i \neq \bar{i}\end{array}$} & \multicolumn{2}{|c|}{$\lambda^{i}=\frac{L_{0}{ }^{i}}{L_{0}{ }^{w}}=\mathrm{const}$} & & $\begin{array}{l}\rightarrow 1 \\
\rightarrow 0, \quad i \neq \bar{i}\end{array}$ \\
\hline $\begin{array}{l}\text { Shares of } \\
\text { World }\end{array}$ & $\omega^{i}=\frac{Y^{i}}{Y^{w}}$ & \multicolumn{2}{|c|}{$\omega^{i} \rightarrow$ const } & \multicolumn{2}{|c|}{$\begin{array}{l}\bar{\omega} \rightarrow 1, \\
\omega^{i} \rightarrow 0, \quad i \neq \bar{i}\end{array}$} & \multicolumn{2}{|c|}{$\begin{array}{l}\widetilde{\omega} \rightarrow 1 \\
\omega^{i} \rightarrow 0, \quad i \neq \widetilde{i}\end{array}$} & \multicolumn{2}{|c|}{$\begin{array}{l}\widetilde{\omega} \rightarrow 1 \text { if } \widetilde{s} b>\bar{n} \\
\bar{\omega} \rightarrow 1 \text { if } \widetilde{s} b<\bar{n}\end{array}$} \\
\hline $\begin{array}{l}\text { Shares of } \\
\text { World } \\
\text { Production }\end{array}$ & $\gamma^{i}=\frac{Y_{i}}{Y^{w}}$ & $\gamma^{i}=\omega^{i}$ & $\gamma^{i}=\lambda^{i}$ & $\gamma^{i}=\omega^{i}$ & $\begin{array}{l}\bar{\gamma} \rightarrow 1 \\
\gamma^{i} \rightarrow 0, i \neq \bar{i}\end{array}$ & $\gamma^{i}=\omega^{i}$ & $\gamma^{i}=\lambda^{i}$ & $\gamma^{i}=\omega^{i}$ & $\begin{array}{l}\bar{\gamma} \rightarrow 1 \\
\gamma^{i} \rightarrow 0, i \neq \bar{i}\end{array}$ \\
\hline \multirow{2}{*}{$\begin{array}{l}\text { Export } \\
\text { Shares of } \\
\text { Production }\end{array}$} & $\gamma^{i}=\frac{X^{i}}{}$ & \multirow{2}{*}{$\chi^{i}=1-\omega^{i}$} & \multirow{2}{*}{$\chi^{i} \approx 1-\omega^{i}$} & \multirow{2}{*}{\multicolumn{2}{|c|}{$\begin{array}{l}\bar{\chi} \rightarrow 0 \\
\chi^{i} \rightarrow 1, i \neq \bar{i}\end{array}$}} & \multirow{2}{*}{\multicolumn{2}{|c|}{$\begin{array}{l}\tilde{\chi} \rightarrow 0 \\
\chi^{i} \rightarrow 1, i \neq \tilde{i}\end{array}$}} & \multicolumn{2}{|c|}{$\tilde{\chi} \rightarrow 0, \chi^{i \neq \tilde{i}} \rightarrow 1$ if $\tilde{s} b>\bar{n}$} \\
\hline & & & & & & & & $\bar{\chi} \rightarrow 0$ & $\chi^{i \neq \bar{i}} \rightarrow 1$ if $\tilde{s} b<\bar{n}$ \\
\hline \multirow{2}{*}{$\begin{array}{l}\text { Import } \\
\text { Shares of } \\
\text { Income }\end{array}$} & $\mu^{i}=\frac{M^{i}}{}$ & \multirow{2}{*}{$\mu^{i}=1-\gamma^{i}$} & \multirow{2}{*}{$\chi^{i} \approx 1-\omega^{i}$} & \multirow{2}{*}{\multicolumn{2}{|c|}{$\begin{array}{l}\bar{\mu} \rightarrow 0 \\
\mu^{i} \rightarrow 1, i \neq \bar{i}\end{array}$}} & \multirow{2}{*}{\multicolumn{2}{|c|}{$\begin{array}{l}\tilde{\mu} \rightarrow 0 \\
\mu^{i} \rightarrow 1, i \neq \tilde{i}\end{array}$}} & \multirow{2}{*}{\multicolumn{2}{|c|}{$\begin{array}{l}\tilde{\mu} \rightarrow 0, \mu^{i \neq \tilde{i}} \rightarrow 1 \text { if } \widetilde{s} b>\bar{n} \\
\bar{\mu} \rightarrow 0, \mu^{i \neq \bar{i}} \rightarrow 1 \text { if } \widetilde{s} b<\bar{n}\end{array}$}} \\
\hline & $\mu-\overline{Y^{i}}$ & & & & & & & & \\
\hline $\begin{array}{l}\text { Owned } \\
\text { Shares of }\end{array}$ & $K^{i}=\frac{K^{i}}{}$ & \multirow{2}{*}{1} & $\vec{\kappa}>1$ & \multirow{2}{*}{1} & $\bar{\kappa} \rightarrow 1$ & \multirow{2}{*}{1} & $\vec{\kappa}>1$ & \multirow{2}{*}{1} & $\widetilde{\kappa} \rightarrow \infty, \bar{\kappa} \rightarrow 0$ \\
\hline Dom. Capital & $\kappa-\overline{K_{i}}$ & & $\bar{\kappa}<1$ & & $\vec{\kappa}>1, \bar{\kappa}<1$ & & $\bar{\kappa}<1$ & & $\bar{\kappa} \rightarrow 1, \vec{\kappa}>1, \bar{\kappa}<1$ \\
\hline $\begin{array}{l}\text { Highest Per } \\
\text { Capita } \\
\text { Income } \\
\end{array}$ & $\begin{array}{l}y^{\max } \\
=\max _{i} y^{i}\end{array}$ & \multicolumn{2}{|c|}{$\tilde{y}=\mathrm{const}$} & \multicolumn{2}{|c|}{$\hat{y}=$ const } & & & & $\hat{\hat{y}} \rightarrow \infty$ \\
\hline $\begin{array}{l}\text { Relative } \\
\text { Poverty }\end{array}$ & $\rho^{i}=\frac{y^{i}}{y^{\max }}$ & $\rho^{i}=\frac{y}{\tilde{y}}$ & $=$ const & $\rho^{i}=$ & $\frac{y^{i}}{\hat{y}}=$ const & & $\rightarrow 0$ & & $p^{i}=\frac{y^{i}}{\hat{\hat{y}}} \rightarrow 0$ \\
\hline
\end{tabular}


mobility or (No FDI), and ones in which savers invest randomly in all countries in proportion to population, as described above.

My discussion of these results will focus on what they mean, rather than on much detail of their derivation, since many of them are obvious once you understand their meaning and the model. Despite my best efforts, the notation remains cumbersome, so that just expressing the results in words may be the larger part of my contribution.

Growth effects on population Population shares are the most straightforward, of course, since population growth is exogenous. Without diverging populations, with all population growth rates equal, population shares are simply constant at their initial levels. With diverging populations, however, the country with the largest population growth rate $^{7}$ comes to dominate the world population, in the sense that its share of world population goes to one regardless of how small it may have started.

It is for this reason, I think, that other contributors to the literature on economic growth have tended to ignore the case of diverging populations, dismissing it as converging to a single closed economy. As we will see, and as I noted already in Deardorff (1994), this sweeps under the rug a lot of interesting dirt. For one thing, the countries whose shares of population go to zero nonetheless continue to exist, and their performance matters, not least to them. More importantly, just because a country's share of population goes to zero does not mean that its share of other relevant economic variables also dwindles to insignificance. Such a country may well come to own a significant and perhaps even dominant share of, say, world capital. That is the possibility explored in Deardorff (1994) with diverging populations and exogenous growth, and endogenous growth provides additional mechanisms for it to happen.

Growth effects on income and production To see this, consider what happens to shares of world income and production. Ignoring FDI for the moment, these two sharesdenoted $\omega^{i}$ and $\gamma^{i}$ in Table 2-are equal. With hedonistic countries per capita incomes become constant in the steady state, and with equal rates of population growth this means that total incomes also remain constant relative to one another. With unequal population growth rates but all countries still hedonistic and hence in steady states, the fastest growing population has the fastest growing income, and its share of world income and production therefore also goes to one, perhaps justifying dismissing it as being essentially a closed economy. But if any countries restrain either consumption or population growth sufficiently to be classed as abstemious, then their incomes will grow faster than their populations in the long run and it is possible for their incomes to even grow faster than the fastest growing population. If that happens, especially if the fastest growing population is also hedonistic, as is plausible, then the abstemious country acquires a share of income that eventually approaches $100 \%$.

Which country is it that comes to dominate the world economy in this way? With equal population growth rates the answer is simple. From equation (8h), the growth rate of output is highest for the country that saves the largest fraction of its income, $\tilde{l}$, and its growth rate must also be larger than the common $n$ or no country would be abstemious. Therefore it is this highest saving country, $\tilde{l}$, that asymptotically accumulates a share of world income, $\tilde{\omega}$, equal to one.

If population growth rates are not equal, then there are two growth rates of GNP that compete for being the highest. One is the growth rate of the highest saving country, $\tilde{s} b$ from equation ( $8 \mathrm{~h})$. The other is the growth rate of the fastest growing population, $\bar{n}$. If the former exceeds the latter, then the high-saving country, $\tilde{\imath}$, will again dominate 
the world economy. But if $\bar{n}>\tilde{s} b$, then even though the high-saving country is growing without bound in its own per capita terms, it is dwindling to insignificance compared with both population and income in $\bar{l}$.

Note that in this case the high-population-growth country, $\bar{\imath}$, is itself hedonistic, since if it were abstemious its own rate of growth would exceed $\bar{n}$. Thus we have here a world economy that is not growing in per capita terms, even though there are abstemious countries within it who are enjoying ever-increasing per capita incomes.

Suppose now that capital is mobile. This matters only for the location of capital and therefore production, both of which will now be proportional to population. Shares of world income behave as already described. Shares of world production, however, do not. Instead, these are equal to shares of world population, becoming constant when countries share equal population growth rates and otherwise approaching one in the country with the fastest growing population.

Growth effects on trade Consider now the share of its output that each country exports, and the shares of its income that it imports. With only a single homogeneous good produced anywhere and both buyers and sellers indifferent among those with whom they might transact, the assumption here is that transactions are determined randomly in proportion to amounts of production and income. That is, all buyers buy from all countries in proportion to their shares in world output, while all sellers sell to all countries in proportion to world demand.

With immobile capital, the resulting trade patterns are straightforward. A country's producers sell to its own market only a fraction of their output equal to their country's share in world income, $\omega^{i}$. Therefore they export the rest, which is the fraction $\left(1-\omega^{i}\right)$ of production. Buyers, spending their entire incomes on either consumption or investment, similarly buy from domestic producers only their share of world production, $\gamma^{i}$, and import the rest, the fraction $\left(1-\gamma^{i}\right)$. These results are reported only in column (3) of Table 2, but they are valid in all of the columns without FDI, where they have been used instead together with the above results on income and production shares to report where the trade shares go to zero and one. For example, in column (5), since with unequal population growth and hedonistic countries both income and production shares go to one in the country with highest population growth, this country's trade also falls to zero since it has nobody of any size to trade with. All other countries, on the other hand, sell essentially all their output to the high-population-growth country, and they import equally from it, because of its dominant share of both income and production.

With mobile capital the situation is somewhat different, as already noted above in equation (17). Each country still purchases goods equal in value to its income for the purposes of both consumption and investment, and it buys them at random from other countries in proportion to where they were produced. However, whereas it imports goods for consumption into its own country, most of what it buys for investment is delivered elsewhere, following its own FDI, into other countries in proportion to their populations and therefore in proportion to their shares of capital and output. On the other hand, while a country's own income may now lead to less imports than before, the country will also be importing goods on behalf of its foreign owners of domestic capital. How all these forces balance out is unclear and complex, as equation (17) indicates. But (17) also shows that as long as savings rates do not differ greatly across countries and countries' GNP and GDP are not too far apart, then trade flows will be approximately what they were with immobile capital. Therefore, in column (4) of Table 2, I have shown the trade shares as being approximately the same with FDI as without, 
and I have not tried to distinguish the cases of FDI and No FDI in the remainder of the table.

Growth effects on investment Even more important than trade for the public's perception of the world economy may be the role of foreign direct investment. There are several ways one could measure this, and I have chosen to look at the ratio of capital owned by a country to capital installed in it. Since the former includes capital installed abroad, this does not tell us how much of domestic capital is foreign owned, which I will note separately from the table in the discussion here. Rather, this ratio tells, in the only sense meaningful in this real model, whether a country is a net creditor or a net debtor in world markets. That is, does it own more or less capital than it employs?

Without FDI, of course, this ratio is one. With FDI and also with equal population growth rates, but regardless of whether capital is growing faster than population or not, capital installed in each country will grow at the same rate (since it is invested in proportion to population), while capital owned will grow faster or slower depending on savings. Thus, high-saving countries will accumulate more capital than they can accommodate domestically and will become net creditors, while low-saving countries will become net debtors. This is shown in columns (4) and (8) of Table 2 in terms of the countries that were identified in Table 1 as saving above and below the world average.

With unequal population growth rates, I am pretty sure that the same thing happens, but with one exception. Now the country with the fastest growing population, $\bar{l}$, attracts ultimately $100 \%$ of investment. Thus it becomes the location for virtually all of world capital. If its share of world income is also one-as it is in column (6) and in column (10) if $\bar{n}>\tilde{s} b$ - then its owned and installed capital approach equality. If on the other hand an abstemious high-saving country saves enough to dominate world income, then it will own virtually all world capital, which will be installed in $\bar{l}$. In that case, $\tilde{\imath}$ owns infinitely more capital than is located within it, while $\bar{l}$ owns hardly any. In both cases, all other countries will behave as in column (4).

Growth effects on per capita income Consider finally per capita income. With only hedonistic countries, all converge to steady states in which per capita income is constant, even though, with diverging populations, total incomes grow at different rates. From equation $(8 b)$ we see that if population growth rates are equal, then steady-state per capita income varies only with the savings rate, and is highest for the country that saves the most, $\tilde{l}$. With diverging populations, on the other hand, a country can offset a somewhat low savings rate with a low population growth rate, and the highest per capita income may be found in a different country, one I have called $\hat{\imath}$ in Table 1 . The per capita income of other countries relative to that maximum-what I have called relative poverty $\rho^{i}$-also converges to a constant. How far short of the maximum individual countries fall depends on the variation across countries in savings rates and population growth rates, but it is in any case bounded above zero.

The situation is quite different if any countries are abstemious. Per capita incomes of such countries grow without bound at growth rates that converge to positive constants. Whatever may be the relative ranking of countries by per capita income initially, all that matters in the long run is who grows fastest. That country's per capita income will eventually surpass all others, and it will grow to be infinitely large relative to them. With equal population growth rates, finding that country is easy. From equation $(8 \mathrm{~g})$ it is again the country with the highest savings rate, $\tilde{\imath}$. With diverging populations, however, slow population growth can again boost a country's growth rate, and 
the maximum is achieved by the country I have identified as $\hat{\imath}$. Thus the same parameters, savings and population growth, matter and in more or less the same ways for per capita incomes in abstemious countries as in hedonistic ones. But the implications are now far more dramatic, since the abstemious countries achieve long-run growth and therefore approach infinite per capita incomes.

More importantly, perhaps, if residents of these countries begin to compare per capita incomes across borders, what they will find will be much more startling and perhaps more troubling when they compare to hedonistic countries. All but the residents of country $\hat{\imath}$ will find themselves falling ever further behind it in terms of per capita income. And while other abstemious countries will have the consolation that their own per capita incomes are nonetheless rising over time, hedonistic countries won't even have that to console them.

\section{Prospects for Inequality, Envy, and Resentment}

I asked at the outset what endogenous growth models might tell us about the prospects of future inequality of incomes across countries. Clearly the model here presents a discouraging picture. Like exogenous growth models, this model says that countries that differ in their saving behavior and population growth rates will also differ in the long run in their per capita incomes. That, no doubt, is as it should be. But the endogenous growth model goes on to say that if countries save enough relative to their rates of population growth for endogenous growth to be possible, then these same differences will lead to increasing divergence in per capita incomes across nations. The possibility of endogenous growth itself is certainly a hopeful implication of the new endogenous growth theory. But the accompanying possibility-which is almost inevitable in the very simple model explored here-is less encouraging. For it means that growth could be accompanied by increasing envy across national borders and perhaps international frictions as a result.

By allowing the model to include both international trade and direct investment, albeit in a very simplified and not very meaningful form, the model also suggests the form that these frictions might take. Note that as we move to the right in Table 2, there is a tendency for the trade shares to become more extreme, and also eventually for the same to happen to some of the owned shares of capital. That is, as savings and population growth parameters become more diverse and abstemious, not only does international per capita income inequality increase; some countries also find themselves depending ever more heavily on trade and, if permitted, on international investment. For example, in columns (3) and (4), export and import shares converge to constants between zero and one. In all other columns, however, the trade shares of all but one country go to one, because all but the largest countries find themselves relying almost exclusively on a single other country to market their products and to source their consumption and investment needs. In some cases though not all, this other country is also one whose per capita income is growing infinitely large relative to their own.

With international investment, this reliance on a foreign, richer, country may be even more pronounced. Consider the case of country $\bar{l}$, whose population grows faster than any other country. If the highest saving country, $\tilde{l}$, grows even faster $(\tilde{s} b>\bar{n})$, then the owned share of capital in $\tilde{\imath}$ goes to infinity while that in $\bar{l}$ goes to zero. What this means is that, in the most populated country, the share of capital owned by foreigners approaches $100 \%$. The high-saving country may not be the richest in the world ( $\hat{\imath}$ may be some other country with a lower population growth rate), but it is surely richer than $\bar{l}$. Thus the huge population of the poorer country finds itself becoming 
ever poorer relative to the high-saving country, and because of the latter's ownership of most of its capital, it may feel exploited by it. This is surely a recipe for resentment and worse.

This is a baleful picture I have painted, and one that draws heavily on some very extreme and nonstandard assumptions. Obvious candidates for questioning are my assumptions that population growth and savings parameters are constant and that international trade and investment occur randomly and as a matter of indifference. In the next section I examine each of these assumptions to see whether they are too severe to permit my analysis any credibility.

\section{Evaluation of Assumptions}

Clearly the assumptions just mentioned are either uncharacteristic of the real world, or unusual in the growth literature, or both. The question is whether they seem likely to have driven the results in ways that more plausible or familiar assumptions would not. I can give no sure answer to that question without actually building and solving the models that these assumptions were in part selected to avoid. But a brief discussion of each can suggest, I think, that the message of the simple model is robust.

\section{Constant Savings Rate}

Early growth models like Solow's (1956) that assumed constant savings propensities were soon replaced by models with one form or another of optimal savings behavior. However, tractable versions of these models have replaced the simple constant savings rate with even more implausible assumptions about individual's preferences and biology, such as infinite lives with constant time preference, or two-period lives with ineffectual retirement. And they have not really altered the key feature of the constant savings rate that drives results in this model: that individuals with different attitudes toward the future will save different fractions of their incomes, even in otherwise similar economic circumstances. If differences in culture across countries continue to lead people to save differently, then the aspects of economic performance explored here, which depend on such differences in savings, seem likely to continue to play the sorts of role ascribed to them here. The only way out of this that I can see is for increasing economic interaction through trade and investment to so homogenize world cultures that such differences across countries disappear.

\section{Constant Population Growth Rate}

The assumption of a constant population growth rate is more standard in the literature on economic growth than the constant savings rate, but it is probably less justifiable for the purpose of this paper. Evidence abounds that birth rates and death rates, on which population growth depends, vary with income, and in particular that population growth rates are likely to fall as real per capita income rises sufficiently beyond subsistence. This obviously would matter a great deal for the results in this paper. However, a moment's thought suggests that allowing for this would only make matters worse. Countries could now differ in their population growth rates because of their differences in income, and those differences in population growth would then exacerbate the differences in per capita income. One does not need this paper to raise concern about the long-run implications of such a mechanism, but it certainly does not assuage concern. 
In addition, just as cultural differences across countries might be expected to maintain differences in long-run savings rates under any plausible theory for determining them endogenously, so too will cultural differences cause population growth rates to differ.

\section{The Meaningless Model of Trade}

The model of international trade that I have used in this paper is really no model at all. By having all countries produce the same homogeneous good and trade it randomly, I have avoided all of the usual reasons for trade, such as comparative advantage, increasing returns to scale, product differentiation, and so forth. Along with many of these familiar theories of trade go both sources of gain from trade, and possible costs of trade (such as factor dislocation) that my approach also excludes. If these benefits and costs could ever be big enough to swamp the effects of growth that I have looked at, then my results would deserve little confidence.

However, long experience with traditional models of international trade suggests that the static welfare effects of trade are comparatively small, and therefore unlikely to outweigh the effects of growth. More recent models of the New Trade Theory, with their increasing returns to scale, offer the chance for larger welfare effects, but to some extent my choice of the AK model to represent endogenous growth was precisely to capture some of these effects. In any case, it is not obvious to me how allowing more explicitly for increasing returns could undermine the implication of this paper about increasing inequality.

Still, to comfort those who may find my meaningless trade model unsettling, let me note that other more conventional models do exist that ought to behave just like it. The simplest is a variant of Krugman's (1979) model of monopolistic competition.

A monopolistically competitive trade model Suppose, then, that countries do not after all produce a single homogeneous good, but rather that they produce a potentially unlimited number of differentiated products, each by a single firm, $f$. Products enter a Dixit-Stiglitz (1977) aggregating function with constant elasticity of substitution:

$$
A=\left(\sum_{f=1}^{F^{w}}\left(d_{f}\right)^{\frac{\sigma-1}{\sigma}}\right)^{\frac{\sigma}{\sigma-1}},
$$

where $F^{w}$ is the number of firms in the world, $d_{f}$ is the quantity an agent demands of the differentiated product of firm $f$, and $\sigma$ is the elasticity of substitution among varieties. I assume this function to be the same in all countries, the aggregate being equally usable for consumption and investment. Production by a firm requires use of an input that is the same linear composite of labor and capital specified in equation (1) for the one-sector model. The amount of this composite needed by a firm is given by a cost function that includes both a fixed-cost and a constant marginal cost component: $c=\alpha+\beta x_{f}$, where $x_{f}$ is the output of the firm and $\alpha, \beta>0$ are constants. With this formulation, as is well known, demand for each firm's product will have constant elasticity, causing each to price its product with a constant markup over marginal cost. Free entry drives profits to zero, leading each firm to produce the same output and employ the same inputs (except in this case that they may have different mixes of capital and labor, which are perfect substitutes). Output of the (single) industry expands and contracts, not by varying the size of firms, but by entry and exit of identical firms. 
This model behaves exactly like the one-sector model of section 2 . However, now instead of buyers being indifferent among sellers of a homogeneous product, they actually prefer equal amounts of each firm's output in order to maximize their Dixit-Stiglitz aggregator in the face of equal prices. This in turn requires that they buy from each country in proportion to its number of firms, and thus its output, which is exactly the result that the random trade mechanism of section 2 led to through the law of large numbers. Therefore one can regard the meaningless trade model of section 2 as equivalent to a Krugman-style one-sector model of monopolistic competition.

There is one difference, however, that should be noted. The model now will have a form of increasing returns to scale. This arises not through the technology of the firm, whose increasing-returns component has been deactivated by the constant elasticity assumption of demand that leads all firm outputs to be the same. Rather, increasing returns arises here from product variety, since an expansion of output through entry of additional firms increases the value of the Dixit-Stiglitz aggregator more than in proportion to $F^{w}$. This does not invalidate anything said about the one-sector model, except that $y$ is no longer a correct measure of real income, which instead rises more than in proportion to $y$. This would mean, for example, that even hedonistic countries with constant $y$ in the steady state would enjoy increasing real incomes over time owing to increased product variety, both from their own producers if their population grows at all, and from the world. And since this variety benefits them just as much if it is produced abroad as at home, this would provide a spillover across countries that was not present in the one-sector meaningless trade model.

Rather than pursue these implications here, however, I merely note that they can just as easily be removed. Suppose that the aggregator of the differentiated products takes the following form instead of equation (18):

$$
A=\left(F^{w}\right)^{\frac{-1}{\sigma-1}}\left(\sum_{f=1}^{F^{w}}\left(d_{f}\right)^{\frac{\sigma-1}{\sigma}}\right)^{\frac{\sigma}{\sigma-1}} .
$$

As shown in Brown et al. (1996), this form of the aggregator neutralizes any benefits of increased variety.

Other trade models There is at least one other way that the meaningless trade model of section 2 can be reinterpreted to conform more closely with meaningful trade models with which we are familiar. That is to assume that each country produces a different homogeneous product. This could simply follow from an Armington Assumption, that demanders in their own minds somehow differentiate products by country of origin. Or it could follow from a general version of the Heckscher-Ohlin $(\mathrm{H}-\mathrm{O})$ model if factor supplies differ sufficiently for each country to be completely specialized in a different product. ${ }^{8}$ In either case, although each country will produce only one good, all will demand the products of all countries and therefore will also export their own products to all others as well.

The H-O approach could become tricky as factor endowments then change in the growth model. But note that in the cases of greatest concern, with abstemious countries growing at different rates, their capital-labor ratios will in fact become increasingly different.

Another issue that arises with using either the Armington Assumption or complete specialization in $\mathrm{H}-\mathrm{O}$ to reconcile with the one-sector model, however, is relative prices. As a fast-growing country pours more and more of its product on to the world market, its price will fall. Indeed, to look at just one simple case, if aggregators 
for both consumption and investment are identical Cobb-Douglas functions, then each country's share of world output at world prices will be constant, equal to the exponents of the Cobb-Douglas function. This constancy is achieved by the price of any country's product falling in proportion to any increase in its output. Therefore much of what may have been interesting about Table 2 would be invalidated. However, as this case may suggest, it seems likely that such a model would conform increasingly closely to the one-sector model of section 2 if aggregators had constant elasticity of substitution (CES) and if that elasticity were taken to be very large. Indeed, I suspect that the one-sector homogeneous product model of section 2 is just the limiting case of such a CES Armington or specialized $\mathrm{H}-\mathrm{O}$ model as the elasticity goes to infinity.

\section{The Model of International Investment}

I assumed in section 2 that if international direct investment were permitted, capital would be allocated at random in proportion to population. That may have seemed especially arbitrary. However, it too can be justified as a limiting case of a more familiar model.

Suppose that the linear production function of equation (1) is replaced with a CES function of labor and capital with elasticity of substitution $\sigma^{L K}$. This function will have a return to capital that is not constant, but that instead depends negatively on the capital-labor ratio, $k$. With freely mobile capital, investment will flow to any country with a lower $k$ than others, since its return to capital will be higher, and therefore in equilibrium all capital-labor ratios will be the same. This is of course a different model than considered above, but as $\sigma^{L K}$ is taken to be larger and larger, it will approximate the linear technology of equation (1).

\section{Conclusion}

The conclusion that I draw from this analysis is not, as you might think, that the world is in trouble. I do believe the model when it tells me that, for certain parameters of behavior, a plausible future would include ever-increasing international income inequality accompanied by increased trade and investment that might be blamed for that inequality. But the model does not tell us what the parameters of actual behavior really are, and on that account I remain agnostic. I have not examined actual technology, savings, and population growth parameters to see where they may lie in the context of this model, and I would not trust such a simple model to quantify real world behavior in any case. ${ }^{9}$

Instead, I take some reassurance from the fact that recent literature attempting to find evidence of endogenous growth in the real world has not been notably successful. In particular, several recent papers, most notably Jones (1995a,b), have sought empirical evidence that incomes of countries have diverged over recent decades, as they should have if endogenous growth models were correct, and they have found that the time series evidence does not support the predictions of endogenous growth models. On the basis of that, I conclude very tentatively that both the hope and, as I have argued, the specter of endogenous growth may be downgraded among our priorities for further analysis.

\section{References}

Barro, Robert and Xavier Sala-I-Martin, Economic Growth, New York: McGraw-Hill (1995). Brown, Drusilla K., Alan V. Deardorff, and Robert M. Stern, "Modelling Multilateral Trade Liberalization in Services," Asia-Pacific Economic Review 2 (April 1996):21-34. 
Deardorff, Alan V., "Trade and Capital Mobility in a World of Diverging Populations," in D. Gale Johnson and Ronald D. Lee (eds.), Population Growth and Economic Development: Issues and Evidence, Madison, WI: University of Wisconsin Press (1987):561-88.

_ , "Growth and International Investment with Diverging Populations," Oxford Economic Papers 46 (1994):477-91.

- "Rich and Poor Countries in Neoclassical Trade and Growth," Research Seminar in International Economics discussion paper 402, University of Michigan (1997).

— , "Determinants of Bilateral Trade: Does Gravity Work in a Neoclassical World?" in Jeffrey Frankel (ed.), Regionalization of the World Economy, Chicago: University of Chicago Press (1998).

Dixit, Avinash K. and Joseph E. Stiglitz, "Monopolistic Competition and Optimum Product Diversity," American Economic Review 67 (1997):297-308.

Fisher, Eric O'N., "Growth, Trade, and International Transfers," Journal of International Economics 39 (1995):143-58.

Galor, Oded, "Convergence? Inferences from Theoretical Models," Economic Journal 106 (1996):1056-69.

Jones, Charles I., "R\&D-Based Models of Economic Growth," Journal of Political Economy 103 (1995a):759-84.

, “Time Series Tests of Endogenous Growth Models," Quarterly Journal of Economics 110 (1995b):495-525.

Krugman, Paul R., "Increasing Returns, Monopolistic Competition, and International Trade," Journal of International Economics 9 (1979):469-79.

Long, Ngo Van and Kar-yiu Wong, "Endogenous Growth and International Trade: A Survey," in Bjarne S. Jensen and Kar-yiu Wong (eds.), Dynamics, Economic Growth and International Trade, Ann Arbor, MI: University of Michigan Press (1996).

Lucas, Robert E., Jr., "On the Mechanics of Economic Development," Journal of Monetary Economics 22 (1988):3-42.

Romer, Paul M., "Increasing Returns and Long-Run Growth," Journal of Political Economy 94 (1986):1002-37.

Solow, Robert, "A Contribution to the Theory of Economic Growth," Quarterly Journal of Economics 70 (1956):65-94.

\section{Notes}

1. See Romer (1986) and Lucas (1988) for the seminal contributions, and Barro and Sala-iMartin (1995) for a comprehensive treatment of the new growth theory.

2. In quite a different approach to a similar problem of international inequality, I have examined a neoclassical growth model in Deardorff (1997), showing that large enough differences in factor endowments can lead both to the failure of factor price equalization and to multiple steady states. The latter, as in Galor (1996), imply the existence of poverty traps, where per capita incomes differ permanently and substantially, not because of differences in behavior but because of differences only in initial conditions.

3. See Long and Wong (1996) for a survey of models of endogenous growth and international trade, where the AK model is carefully explained.

4. Solow's model, of course, allowed a more general production function than (1), $Y=F(K, L)$ $=L f(K / L)$ with constant returns to scale. It became the AK model if $\lim _{k \rightarrow \infty} f^{\prime}(k)>n$.

5. $K_{i}$ is "on the ground," if you like, and thus the subscript.

6. Interestingly, no extra conditions are required for the exporting country.

7. I will assume for this and other identifications of countries with the highest levels or rates of variables that they are unique. In many cases, like this one, if more than one country were to tie for the maximum, we could redefine countries to combine them.

8. Fisher (1995) has examined an AK growth model with two countries that focuses more on situations of incomplete specialization. 
9. Actually, I did on one occasion, in Deardorff (1987), attempt just such a quantification. Using a version of the model in Deardorff (1994), modified to better capture certain features of the data, I simulated long-term growth using savings, population growth, and other parameters from the developed and developing worlds. What I found was not suggestive of endogenous growth. 